\title{
A Redemptive Analysis of Suffering
}

\author{
Daihyun Chung \\ Ewha Womans University
}

\begin{abstract}
The notion of suffering carries with it aspects which are private and individual on the one hand, and social and lingual on the other. I would pay attention to the latter part of the suffering notion, where the notion of suffering is recognized to be primitive by almost all the theories of human values. This primitive character allows a commensurable basis on the basis of which most plural theories share something in common to talk objectively to each other. In this paper, I would like to offer three arguments in order to advance a thesis that one's suffering is redemptive of others. First, the conservation law of mass says that matter of a closed system can neither be created nor destroyed, although it may be differently rearranged. This may be applied to the experience of suffering, to allow the conservation law of suffering: My unjust self-interest costs pains in others to the level of the same amount but if I voluntarily suffer a sacrifice, others will have their pains lightened to the analogous level. Second, notion of yin-yang helps to support the redemptive thesis of suffering. The notion says that all things in the reality consist of two complementary opposite capacities that interact within a greater whole, as part of a dynamic system. Then, my acceptance of suffering and the decrease of other's pain are two complementary capacities of one reality. Third, any person is responsible for his own act, so is a society as a whole. Then, as an individual restores his damaged person, when he commits a crime, by being suffered or punished, a society restores itself to its own proper state, when any member of the society is wronged, by suffering communally in one way or other.
\end{abstract}

Keywords: suffering, redemptive, conservation, yin-yang, responsibility, sharing, solidarity

\section{Opening: Suffering Relational and Redemptive}

There is a novel called Please Look after Mom by Kyung-Sook Shin (2011). Shin portrays a mother who suffers many difficulties for the betterment of her children, and toward the end of the novel, she juxtaposes images of the mother's suffering with images of Michelangelo's Pieta which is shown at St. Peter's in Rome. The result seems to imply that all mothers in the human history suffered hardships for the sake of redemption of pains of their children. Then, I come to wonder why not to generalize the implication further. Thus it arises my thesis of this paper that one's suffering is redemptive of others.

There are some philosophers who are positive toward my thesis. For an example, Leibniz (1996, 182-90) believes that suffering is good because it incites human will and says that sufferings are there not because God desires them to be there but because God allows them. Scheler (1992) is more helpful for my claim. For, he insists that all sufferings have meaning as sacrifice (Opfer). To him, all sufferings of members of a community are aimed as sacrifices for the well-beings of the whole of the community. An individual is said to suffer or die substitutionally for the sake of the whole.

Daihyun Chung, professor emeritus, Ph.D., Department of Philosophy, Ewha Womans University, South Korea; main research field: Philosophy of Language, Philosophy of Mind, Analytic Metaphysics, and Epistemology. 
In this paper, I recognize that the notion of suffering has physical aspects as well as psychological ones, but I would like to make a further distinction in the psychology of suffering, which is the distinction between the object and the meta levels. When one suffers, it takes a form of an object in the sense that the experience of suffering has an aspect which is only privately intelligible. But as the experience-content of one's suffering is subject to public scrutiny, it will display meta characteristics since any mental language has only a social criterion for its application. I will pay attention in this paper to the meta aspect of suffering, assuming that the content of suffering at this level is social. In this sense, our mothers suffer many kinds of socio-lingual afflictions to relieve pains of their children. The notion of pain reflects one's bodily sensation or feeling but it also contains some propositional content. Then, I will try to propose a relation between notions of suffering and pain in such a social way that one suffers on behalf of reduction of pains in others, in order to give three arguments to advance my thesis. But before I go into the main arguments, I would like to show how the subject of suffering is important.

\section{Significance of Suffering: Its Primitiveness}

Why are there sufferings? A Buddhist tradition is that bodhisattva (菩薩) teaches that one does charity work to help others to be Buddha before she herself becomes a Buddha. Christianity places Jesus' crucifixion in the center of the history of salvation, thereby interpreting the notion of suffering extensively and teaching that one accepts suffering in order to lessen other's pains. But Nietzsche $(1966,225,270 ; 1974,3)$ thinks that happiness is not a criterion for being a higher person, allowing that free spirits will be cheerful or gay. Instead, he observes that suffering makes us more profound, necessary for the cultivation of human excellence though suffering is not intrinsically valuable. I tend to think that a religious view of suffering is wholistic and communal whereas Nietzsche's view is individualistic and private.

If I have to support the thesis of redemptive suffering, there should be a way to avoid the Nietzschean view of suffering. People seek for happiness. But when they undergo pains, priorities become obvious. Elimination of pain comes ahead of achievement of happiness. This seems to suggest that pains are primitive, in the sense that any human value theory should require that pain needs to be eliminated. A theory cannot afford to ignore this basic condition. For, if it can afford it, it could not be called "a human value theory." Then, in spite of the situation that there are pluralistic theories of values, they share a basic value, which is the primitiveness of pains.

But why should I accept the thesis of priority of the pain elimination over the happiness pursuit? One can find a positive support in the philosophy of science, where falsification is dominant over to verification. For, the falsification thesis says that truth of a proposition cannot be ascertained here and now, but its falsity can. For, any sentence in a scientific system is accepted for a while not because it is found to be true but because it is not shown to be false, by variously attempted experiments. That's why the sentence is called a hypothesis, not $a$ truth. The falsification thesis can also be applied to the social phenomena. It would seem to be impossible to reach a consensus as to what should be the condition for happiness for all people in a community, but it would not be difficult for a community to come to an agreement as to what should be the priority of values one of which is elimination of pains.

Confucius' (1999) notion of seo (怒) may help to see the priority thesis. The notion literally means forgiveness, but Confucius himself clarifies what he means by the notion of seo, saying that one does not do to others what she does not want to be done to herself (己所不欲勿施於人). This is one way of expressing the 
golden rule. But why does Confucius say the golden rule in a difficult mode of double negation? Some scholars interpret Confucius's expression as saying the one and same golden rule. But I do not think that Confucius would agree with the interpretation. He should have a reason to say the golden rule in the sophisticated manner. What's called the "positive" golden rule (treat others in the way you want to be treated) has the appearance of equal exchange treatment, as in a vending machine, not primarily indicating any interest in other's person or in any human solidarity. But Confucius's "negative" golden rule shows a deep interest in other's personhood, in taking other as the same human as she. Confucius seems to have taken the human solidarity as consisting of the priority of the pain elimination over the happiness pursuit.

The primitiveness of pain may be the basis from which we reach some sort of objectivity or connectivity among theories of morality in the age of pluralism. Then the fact that humans share pain as one primitive notion allows "the Archimedean point" where human ethical discourses may maintain some objective structure. Now I can attempt to give one answer to Nietzschean view of suffering. My answer is to be found in the role which the notion of pain plays among various ethical theories to allow them a commensurable basis for inter-theoretic dialogues. This notion of pain's being primitive allows something in common among those plural theories in such a way that they can be objectively commensurable. ${ }^{1}$

\section{An Idea of Conservation}

The conservation law of mass says that mass in a closed system is neither created nor destroyed though it may be differently rearranged. Bong-Ho Sohn $(1995 ; 2000)$ applies the conservation law of the physical world to the experience of suffering of the social world, calling it "the conservation law of suffering:" (S1) My unjust self-interest (pleasure) costs pains in others to the level of the same amount, but if I voluntarily suffer a sacrifice, others will have their pains lightened to the analogous level.

Of course, there are huge disanalogies between the conservation law of mass and the conservation law of suffering, which are recognized among the natural phenomena and the social phenomena. Disanalogies between the two can be seen under the subjects like extension, truth-functionality, projectibility, intension, and the like. But what we can gain from the comparison of the two law statements is greater than the difficulties we may undergo due to the disanalogies of the two.

What do we learn from the analogies of the two? Suppose that we accept the conservation law of suffering. Then, we can lessen pains of others as much as we willingly accept our sacrifices on our part. Our sufferings can be redemptive of pains of others. Of course, this suffering is the one to be defined in terms of what one would argue in order to support the law statement of suffering.

The conservation law of suffering may be found working in various fields of the human experience. I would like to pay attention to some of them. Currency is one of our interesting examples. The total amount of money currency is fixed at any given time. But opportunities for the access to the currency are not equally distributed among members of the society. The strong persons enjoy more or bigger opportunities in the society but the weak ones have fewer or less opportunities. Then, the strong ones in our society need to be reminded of what the conservation statement of suffering tries to convey.

Ecology is another subject for our reflection. Vegetarianism writes that if there is an alternative means, one needs to avoid unnecessary suffering to animals. What would be the basis for such a belief? There are a few views on it. Singer $(2001,35)$ holds that there is continuity between humans and animals so far as these animals display abilities of feeling pleasure and pain enough so that they are the object of human moral 
consideration. Naess (1989) insists that any life itself is significant so that I am more than my body and my mind, in order to deserve to be Self in the capital S which includes everything. Taylor $(1993,74)$ entertains an idea that everything, conscious or not conscious, constitutes a system which moves teleologically so as to preserve its own self and well-being. Sok-Hon Ham (1993, Vol. 14, 323-57) is very metaphysical in formulating his philosophical world view. Ssial (種子), literally translated as "seeds," are spirits which reside in matter, are infinites which live in finites, and are eternity which are contained in things of temporality. Ham applies vitality of life to things in the organic world as well as in the inorganic world, and subsumes all of them under a concept which he calls oneness. And Ham goes further to say that these ssial are subjects of life and meaning which are united with the history through their participations of others' pains. As one can allow what some ecologist interests' claim, which is that humans and natures are continuous, it becomes clearer that my avarice means pains in others.

Another case of the conservation law of suffering is obtained in a Korean idiom which translates as other's suffering is a medicine for my suffering. It implies that whenever I witness others in deep suffering, I feel my suffering relieved. This medicine case does neither look rational nor moral, at least on its surface (Apple 2008). But the medicine case may be re-described as following: I feel my suffering lessened whenever I witness that others consequently or de facto participated in my suffering through their sufferings though they do not intend it. If we can accept this re-description, we can locate the locus where the consolation takes place. It seems to be where a shift is made, a shift from the solitude of suffering to the solidarity of shared suffering. One may deny the plausibility of the re-description. But if there is a reason for the denial, I wonder what it would be. But until the reason for the denial is coming forward, then the case of the re-description is sustainable. And one remembers that people often console their friends under suffering by telling them stories of how others undergo deeper sufferings. I believe that these stories are legitimate and efficient way to lessen sufferings of them.

The medicine case appears to be helpful in revising the voluntary condition which the law statement of suffering (S1) requires. The one who suffers in the medicine case does not need to suffer voluntarily so that others may relieve their pains. The cases of Currency and Ecology discussed above appear to support the manner of revising the voluntary condition as following: (S2) My unjust self-interest (pleasure) costs pains in others to the level of the same amount, but in connection with pains of others if I voluntarily or otherwise suffer a sacrifice, others will consequently have their pains diminished to the analogous level.

The phrase "in connection with pains of others" in (S2) needs a clarification. If there is no phrase like this in the condition, the relation between the acceptance of suffering and the elimination of pains remains open and not concrete. Then, a question is valid, which is, whether any kind of acceptance of suffering can lessen any other varieties of pains. These two need to be connected and the two can be related by a chain of causation or someone's awareness of the two events under consideration.

\section{Consideration from a Yin-Yang Perspective}

The thesis of redemptive suffering can be supported by a conception of yin-yang. The notion of yin-yang looks to be an alternative world view, as theories of dualism or of physicalism appear more and more weakening in the contemporary philosophical scene (Chalmers 1996). For an example, these are not capable of explaining a notion like bodies as mind-realizers or smart phones as extended minds. For, they do not believe that two different substances can maintain a relationship of realization of one by the other. But the notion of yin-yang has maintained that any event or anything consists of yin-yang, two complementary opposites that 
interact within a greater whole, as part of a dynamic system. "Yin-yang (陰陽)" literally means shadowed-lighted and their logic works organically not only within a thing internally but also in a thing externally with its environments. The notion of yin-yang also interprets mind and body in human beings not as two opposite dualities but as two capacities which interact with each other (Chung 2008, 33-40). This logic of the notion can be extended to the realm of the social phenomena, taking any relation among members of a society as a unit of the wholesome integration of the greater total organism. Then, it is inviting to say from this perspective that one's suffering is redemptive of pains of others.

Democracy may be a subject which can be analyzed from a view of yin-yang. ${ }^{2}$ Democracy is understood as a form of people's governing through the process of voting. People's governing may be direct or representational but the people's voting for a decision is made by the majority rule. The decision may be reached by a process of people's preferences or of people's deliberate consideration. But there is no other way to reach the decision except through the majority rule. Then, democracy is a system which always left the minority behind by the majority rule. There are cases of unanimity but they are exceptional than a rule. Then, when a community makes a decision, democracy demands its members that the majority lead and the minority follow. Any consensus is bound to contain a room of exclusion.

It would be useful to read exactly what is at work in the logic of majority's leading and minority's following upon any democratic decision. Elitist philosophy of politics like Plato's criticizes democratic processes as populist. For, the relation of leading and following will eventually lead to moments like a distancing between consensus and exclusion, a conflict of interests. But there is a way to read the same democratic processes in terms of yin-yang. The majority rules of democracy do not require that the fate of a community is decided by the one and only one event of voting. It rather consists of a series of voting as to institutional establishments, officer appointments, policy revisions, hearings, and so on. And members of the community are to be informed and conscientious voters as they are open to all the sufficient information and to various opportunities of discussions of the relevant topics and viewpoints. Then it is important to note that just as yin-yang are not two separate substances but ever-exchanging flexible powers, any events in the democratic processes are also ever-exchanging capacities to interact with each other. Democracy has been opted for not because it is a perfect system of people's governing at a given time but because it is the only available system which people can depend on. Then, the relation of leading and following reflects integrated capacities of all kinds in their organic wholesomeness. If the yin-yang interpretation of democracy is plausible, the following statement is what I would recommend. (S3) My acceptance of suffering and the decrease of other's pain are two complementary capacities of one reality.

\section{A Conception of Responsibility}

The thesis of the redemptive suffering can also be read in terms of the conception of responsibility. Responsibility is one of the major properties of the human action. If a human act is significantly meaningful, a society asks the agent of the act to explain for its responsibility. The agent is rewarded if the act is positively meaningful, but he is punished if the act violates a communal criterion. Pain is derived from a Latin word, poena, which means punishment. ${ }^{3}$ The etymological relation between pain and punishment may be a basis from which a common sense is derived, namely, that anyone who gives a human some pains should take some equivalent pains back. But this common sense can be re-described into a Kantian perspective: Anyone who gives a human some pain results to damage his own person and then he needs to restore his person in the 
rightful state back by being suffered (punished). If we can accept such an interpretation of punishment, we can reach the conception of the responsibility that "being responsible" means "improving his own person or restoring his damaged person by accepting sufferings (punishments)."

We may go further to pay attention to the notion of responsibility on the social dimension. Crimes are committed mostly by individuals. But it is also said that these individual crimes are expenses which the society should pay for the sake of modifying institutions and policies in order to improve the society. Then, the so-called "criminals" are nothing more or nothing less than agents who are constructed in the course of paying the expenses. We have already observed that it would be difficult to separate the predicament of individuals from the realm of the society in the strict sense as the conservation law of suffering and the yin-yang thesis suggest. And one is apt to accept a Kantian interpretation ${ }^{4}$ that the meaning of punishment for the offence of an individual is the restoration of his person to the state before his offence. Then, the payments for the expense due to crimes on the part of the society may be taken as a part of processes where the society is integrated to a wholesome stage.

One characteristic of the notion of responsibility needs to be clarified in the context of supporting the redemptive character of suffering. During the primitive ages of the human history, east or west, there have been sacrificial rituals in order to redeem the wrongs committed by an individual or a communal entity. They burned a pigeon, sheep, cow, or even a human, in believing that their offences can be substitutionally forgiven. They did not know that there was no conceptual connection between their own offences on the one hand and the living body itself which was offered as a sacrifice on the other. They just assumed that the deity would grant the conceptual relation between the offender and the offering which was forced to assume the other's responsibility. Still, we have a trace of this past superstition in a popular use of the word scape goat. Fortunately, our contemporary notion of responsibility is mature enough to be agent-centered. Then, the following statement seems to be attractive. (S4) The relation of crimes and punishments is integrational at the level of an individual concerned, whereas the relation of one's acceptance of suffering and lessening of other's pains is integrational at the level of community.

\section{Concluding: Capitalism and Conservationism}

Capitalism is not something we can avoid in the present world. But the notions of capacity and competition on the ideas of which capitalism is based need to be constrained. The shadow of the polarization between the Haves and the Have-nots has been deteriorated worse and worse. The world is no longer a world where an individual can be happy with his own happiness alone. The world is a world in which human beings live together with each other. The notion of suffering is worthy of considering as primitive for the world we live in. This redemptive suffering is a value by which one can recognize the human solidarity, with which capitalism can be revised, which can give substance to the way how democracy works. It is one of the basic conceptions where the market can be made humane and democracy may be concretely embodied.

Then, my treatments of statements (S1) through (S4) may lead to a conclusion, which I would like to call conservationism of suffering, that is: (S5) The relation between one's acceptance of suffering and the reduction of pains in others reflects a redemptive property of the human world where all human beings can relate to each other. $^{5}$ 


\section{Notes}

1. This commensurable notion of pain looks to have been conceptualized in systems like hospital ambulance, police emergency call, Red Cross, and Red Crescent.

2. Moomok Yang, "Yin-Yang as Redeemer and Democracy," Dsesoon Thought Nonchong, Daejin University, South Korea, Vol. 2 (1996): 153-239 (in Korean). Mr. Yang gives a list of human dignity, freedom, equality, and social justice, as democratic concepts which are illuminated by yin-yang logic, 212-4.

3. Merriam Webster: Pain- from Anglo-French peine, from Latin poena, from Greek poinē payment, penalty; akin to Greek tinein to pay, tinesthai to punish, Avestankaēnā revenge, Sanskrit cayate he revenges.

4. Immanuel Kant, Metaphysical Elements of Justice, translated by John Ladd, 2nd Edition, Hackett Publishing, 1999, 139: "But what is meant by the statement, 'If you steal from him, you steal from yourself?' Inasmuch as someone steals, he makes the property of everyone else insecure, and hence he robs of himself of the security of any possible property."

5. This work was supported by the National Research Foundation of Korea Grant funded by the Korean Government (NRF-2010-342-A00005). A draft of this paper was read under the title "A Conceptual Analysis of Suffering: How One's Suffering Is Redemptive of Others?" at the 2nd Global Conference on Suffering-A Making Sense of, Prague, Czech Republic. $<\mathrm{http} / / / \mathrm{www}$.inter-disciplinary.net/probing-the-boundaries/making-sense-of/suffering/call-for-papers/>.

\section{Works Cited}

Apple, Dennis. Life after the Death of My Son. Boston: Beacon Hill Press, 2008.

Chalmers, David. The Conscious Mind: In Search of a Fundamental Theory. New York: Oxford University Press, 1996.

Chung, Daihyun. "Intentionality of Cheng (誠): Toward an Organic View.” Philosophy and Culture: Metaphysics. Seoul: Korean Philosophical Association, 2008. 33-40.

Confucius (孔子: BC 552-BC 479), The Analects of Confucius (論語, LúnYǔ). Trans. Roger T. Ames, Henry Rosemont, Jr. New

York: Ballantine Books, 1999.

Ham, Sok-Hon. Ham Sok-Hon's Comlete Works, Vol. 14. Seoul: Hangilsa, 1993 (in Korean).

Kant, Immanuel. Metaphysical Elements of Justice. Trans. John Ladd, 2nd Edition. Indiananpolis: Hackett Publishing, 1999.

Leibniz, Gottfried Wilhelm, Peter Remnant, and Jonathan Francis Bennett. New Essays on Human Understanding. Cambridge:

Cambridge University Press, 1996.

Merriam-WebsterThesaurus. Springfield, Mass.: Merriam-Webster, 2005.

Naess, A. Ecology, Community, Lifestyle. Trans. and Ed. D. Rothenberg. Cambridge: Cambridge University Press, 1989.

Niezsche, F. Beyond Good and Evil. Trans. W. Kaufmann. New York: Vintage, 1966. 225; 270.

---. The Gay Science. Trans. W. Kaufmann. New York: Vintage, 1974.

Scheler, Max. "The Meaning of Suffering.” Trans. Harold J. Bershady. Max Scheler. On Feeling Knowing, and Valuing. Selected

Writings. Ed. Harold J. Bershady. Chicago: The University of Chicago Press, 1992. <http://www.SchelerSociety.US>.

Shin, Kyung-Sook. Please Look after Mom. New York: Alfred A. Knopf, 2011.

Singer, Peter. “A Utilitarian Defence of Animal Liberation.” Environmental Ethic. Ed. Louis Pojman. Stamford: Wadsworth, 2001. $35 \mathrm{ff}$.

Sohn, Bong-Ho. "Victim-centered Ethics.” Sogang Humanities Nonchong, Vol. 1. Seoul: Sogang University, 2000 (in Korean).

---. Human Being in Pain. Seoul: Seoul National University Press, 1995 (in Korean).

Taylor, Paul. "The Ethics of Respect for Nature." Ed. Michael E. Zimmerman. Environmental Philosophy. Englewood Cliffs: Prentice Hall, 1993. 74ff.

Yang, Moomok. "Yin-Yang as Redeemer and Democracy." Dsesoon Thought Nonchong, Vol. 2. South Korea: Daejin University, 1996 (in Korean). 